\title{
O COLÉGIO DA POLÍCIA MILITAR E O ENSINO DA MATEMÁTICA
}

\author{
Ângela Pereira Gregório ${ }^{1}$ \\ Laudijane Souza Puridade ${ }^{2}$
}

\begin{abstract}
Resumo
Neste artigo apresenta-se a prática do docente e do discente do Colégio da Polícia Militar (CPM), assim como o ensino da matemática, e uma análise da proposta pedagógica do ensino desta disciplina visando desenvolver as potencialidades do educando como elemento de preparação para o trabalho e para o exercício consciente de sua cidadania. Na metodologia desta pesquisa foram utilizadas abordagens qualitativa e descritiva, com a finalidade de compreender de que forma os índices de desempenho em matemática poderiam ser aprimorados no Colégio da Polícia Militar Francisco Pedro de Oliveira (CPMFPO). E após a coleta de informações constatou-se que a necessidade de implementar uma estrutura pedagógica capaz de auxiliar o CPMFPO a alcançar melhores níveis de desempenho no IDEB, assim como um trabalho de conscientização junto aos discentes de forma a incentivar os mesmos a se dedicarem na busca de um melhor rendimento e na expansão de seus conhecimentos.
\end{abstract}

Palavras-chave: Prova Brasil. Matemática. Colégio da Polícia Militar.

\begin{abstract}
This article presents the practice of the teacher and the student of the Military Police College (CPM), as well as the teaching of mathematics, and an analysis of the pedagogical proposal of teaching this discipline in order to develop the potential of the student as an element of preparation for the work and for the conscious exercise of their citizenship. In the methodology of this research, qualitative and descriptive approaches were used, in order to understand how the performance indices in mathematics could be improved at the Military Police College Francisco Pedro de Oliveira (CPMFPO). And after collecting information, it was found that the need to implement a pedagogical structure capable of helping CPMFPO to achieve better performance levels at IDEB, as well as raising awareness among students in order to encourage them to dedicate themselves to search for a better performance and the expansion of their knowledge.
\end{abstract}

Keywords: Brazil Test. Mathematics. Military Police College.

\section{Introdução}

A avaliação da educação básica é um assunto que se faz presente na atualidade, no Brasil o principal marco da avaliação educacional é o Sistema Nacional de Avaliação da Educação Básica (SAEB) que teve início no final da

\footnotetext{
1 Graduada em Licenciatura em História pela Universidade Federal da Bahia- UFBA. Bacharel em História pela Universidade Federal da Bahia- UFBA. Especialista em História e Cultura Afro Brasileira pela FACCEBA. Mestranda pela Faculdade Interamericana de Ciências Sociais- FICS. Docente de História pela Secretária de Educação do Estado da Bahia. Email: angeldois28@gmail.com

${ }^{2}$ Graduada em Arquitetura e Urbanismo pela Universidade Federal da Bahia - UFBA. Graduada em Matemática pelo Centro Universitário Jorge Amado - UNIJORGE. Especialista em Matemática e Novas Tecnologias pela Universidade Católica do Salvador - UCSAL. Mestranda pela Faculdade Interamericana de Ciências Sociais - FICS. Docente de matemática pela Secretaria de Educação do Estado da Bahia. E-mail: laudmatematica@gmail.com
} 
década de 80 e se constitui no principal sistema de avaliação diagnóstica da educação básica brasileira.

Considerando a importância das avaliações externas, em especial da SAEB, a proposta deste projeto é investigar quais fatores podem influenciar nos índices de desempenho de matemática do Colégio da Polícia Militar Francisco Pedro de Oliveira (CPMFPO), Candeias/Ba. Considerando que mesmo sendo uma rede de colégios que fazem parte da rede pública estadual de ensino do estado da Bahia, as unidades da rede Colégio da Polícia Militar apresentam melhor desempenho nas avaliações externas.

Nas escolas públicas de educação básica as políticas de avaliação têm maior evidência, desde a divulgação em 2007, pelo Ministério de Educação e Cultura (MEC) do indicador de avaliação da educação básica, o Índice de Desenvolvimento da Educação Básica (IDEB), determinado com os dados coletados a partir do SAEB e do Censo Escolar. O IDEB passa a ser empregado tanto para nortear o planejamento de políticas públicas educacionais nos níveis municipal, estadual e federal e no financiamento da educação, além de servir como informativo para a população.

O IDEB é calculado a partir da taxa de aprovação e do desempenho dos estudantes na Prova Brasil, avaliação aplicada pelo Instituto Nacional de Estudos e Pesquisas Educacionais (INEP) a cada dois anos. Com base nessas informações, são atribuídas notas para cada escola pública do Brasil, assim como para as redes de ensino e para os municípios e os estados. Cada escola, prefeitura e governo estadual tem uma meta que deve ser atingida de dois em dois anos. (IDEB, 2007)

Pois, considera-se o fator 'desempenho' relacionado ao aproveitamento cognitivo dos estudantes, em Língua Portuguesa e Matemática, e o fator 'rendimento' ao fluxo escolar, determinado a partir da taxa de aprovação medida através da razão entre o tempo necessário para conclusão da etapa de escolarização e o tempo de duração para concluí-la (ALMEIDA, DALBEN e FREITAS, 2013).

Por considerar-se a importância do IDEB em específico, de que forma o desempenho em Matemática pode influenciar no referido índice assim como o desempenho diferenciado das unidades do Colégio da Polícia Militar no contexto da 
educação pública na Bahia, entende-se a necessidade de traçar um perfil da rede CPM, evidenciando o Colégio da Polícia Militar Francisco Pedro de Oliveira (CPMFPO), Candeias/BA, foco maior do referido estudo.

Vale ressaltar que, o contexto cultural escolar em que estão inseridos os estudantes de forma que suas escolhas e sua vivência podem influenciar de forma contundente no seu sucesso ou fracasso escolar, também estão diretamente ligados a transição entre a cultura inerente a suas vidas cotidianas e a subcultura escolar. Mesmo porque cada escola é única, fruto de sua história particular, de seu projeto e de seus agentes. Como lugar de pessoas e de relações, é também um lugar de representações sociais, e:

\begin{abstract}
Como instituição social ela tem contribuído tanto para a manutenção quanto para a transformação social. Numa visão transformadora ela tem um papel essencialmente crítico e criativo. A escola não é só um lugar para estudar, mas para se encontrar, conversar, confrontar-se com o outro, discutir, fazer política. Deve gerar insatisfação com o já dito, o já sabido, o já estabelecido. Só é harmoniosa a escola autoritária. A escola não é só um espaço físico. É, acima de tudo, um modo de ser, de ver. Ela se define pelas relações sociais que desenvolve. $E$, se quiser sobreviver como instituição, precisa buscar o que é específico dela (GADOTTI, 2007, p. 11-12).
\end{abstract}

Consideramos a importância do contexto cultural escolar em que estão inseridos os estudantes de forma que suas escolhas e vivência podem influenciar de forma contundente no seu sucesso ou fracasso escolar, que também estão diretamente ligados a transição entre a cultura inerente a suas vidas cotidianas e a subcultura escolar. Da mesma forma o docente desenvolve relações diferenciadas a depender das especificidades de cada ambiente escolar por onde circula.

Nessa perspectiva é que levantamos a questão de investigação que norteou esta proposta: Como os Índices de Desempenho, em específico, de Matemática podem ser aprimorados no Colégio da Polícia Militar Francisco Pedro de Oliveira, Candeias?

Por tratar-se de um colégio de regime militar, não poderíamos deixar a margem dessa investigação o fator cultural inerente ao referido regime e assim sendo, entendê-lo enquanto uma cultura capaz de influenciar no processo de ensino aprendizagem de forma diferenciada. Assim como o ensino aprendizagem da Matemática apresenta especificidades em cada ambiente onde é trabalhado e a 
partir da origem cultural de cada estudante (SILVA et al, 2016 e D’AMBRÓSIO, 2005).

Assim sendo, quando consideramos o contexto cultural inerente a um colégio militar, imerso em regras e deveres que muitos discentes desconhecem quando oriundos de outras unidades de ensino ou mesmo que não conseguem se adaptar e/ou aceitar em função da cultura individual da qual são oriundos percebemos a influência que a referida cultura escolar pode exercer nas escolhas, sucessos e fracassos de cada discente.

\section{O Docente de Matemática do Colégio da Polícia Militar (CPMFPO)}

O Colégio da Polícia Militar Francisco Pedro de Oliveira (CPMFPO) possui cinco professores que lecionam Matemática tanto no Ensino Fundamental quanto no Ensino Médio, dos quais todos são homens. Dos cinco educadores, quatro são Licenciados em Matemática e apenas um é Bacharel em Construção Civil, conforme Tabela 1, na qual verificamos a instituição aonde o professor realizou seu curso, com base na referida tabela é possível observar que a maioria dos professores de matemática do CPMFPO realizaram seus cursos em instituições de ensino superior particulares.

Acerca do vínculo dos docentes com o colégio, é interessante ressaltar que destes dois são militares lotados no CPMFPO e lecionam como horistas e os demais civis, além disso, apenas um destes professores é funcionário público efetivo, concursados pela Secretaria de Educação e Cultura (SEC) - BA tendo os demais um contrato temporário com a Secretaria de Educação do Estado da Bahia chamado de Regime Especial de Direito Administrativo (REDA) ${ }^{3}$.

\begin{tabular}{c|c|c}
\hline \multicolumn{2}{c}{ Tabela 1 - Formação dos Docentes de Matemática do CPMFPO } \\
\hline Professor & Curso & Instituição de Ensino \\
\hline A - Civil Efetivo & $\begin{array}{c}\text { Licenciatura em Matemática } \\
\text { (Incompleto) }\end{array}$ & $\begin{array}{c}\text { Universidade Salvador } \\
\text { (UNIFACS) }\end{array}$ \\
\hline B - Militar & $\begin{array}{c}\text { Bacharelado em Construção } \\
\text { Civil }\end{array}$ & $\begin{array}{c}\text { Universidade do Estado da } \\
\text { Bahia (UNEB) }\end{array}$ \\
\hline C - Militar & Licenciatura em Matemática & UNIJORGE \\
\hline D - Civil REDA & Licenciatura em Matemática & $\begin{array}{c}\text { Universidade Federal da } \\
\text { Bahia (UFBA) }\end{array}$ \\
\hline E - Civil REDA & Licenciatura em Matemática & UNIJORGE \\
\hline
\end{tabular}

Fonte: Questionário aplicado com os docentes de Matemática do CPMFPO, junho de 2019.

\footnotetext{
${ }^{3} \mathrm{O}$ contrato com prazo determinado de 48 meses, podendo ser prorrogado por mais dois anos, onde ambas as partes contratante e contratado assinam de forma lícita sabendo que não existe vínculo.
} 
Com base na aplicação de um questionário, pudemos certificar que apenas um dos educadores possui especialização em Matemática, além disso, identificamos que dos cinco professores, dois possuem mais de uma graduação e nos últimos quatro anos dois fizeram cursos de aperfeiçoamento, um professor fez um curso de aperfeiçoamento promovido pela SEC - BA, com o objetivo de mudança da faixa salarial.

O CPMFPO no final de 2017 iniciou a implementação de ações para auxiliar na melhoria da qualidade do nível de ensino desenvolvido no colégio, com o objetivo de melhorar seus resultados diante das demais unidades do Colégio da Polícia Militar (CPM), assim como uma atenção especial para as avaliações externas como, por exemplo, o Exame Nacional do Ensino Médio (ENEM) ${ }^{4}$. Na verdade, a Prova Brasil que é uma avaliação externa aplicada no $5^{\circ}$ e 9o ano do Ensino Fundamental e na $3^{\text {a }}$ série do Ensino Médio, constitui-se o foco desta pesquisa.

$\mathrm{Na}$ Tabela 2, apresentamos o tempo de experiência dos professores entrevistados, assim como seu tempo de trabalho no CPMFPO, dado importante a ser evidenciado, pois a rotatividade dos docentes é um ponto influenciador no desempenho dos estudantes em avaliações externas, como o Sistema Nacional de Avaliação da Educação Básica (SAEB).

\begin{tabular}{|c|c|c|}
\hline \multicolumn{2}{|c|}{ Tabela 2 - Tempo de Experiência dos Docentes de Matemática do CPMFPO } \\
\hline Professor & Tempo que leciona & Tempo no CPMFPO \\
\hline A - Civil Efetivo & 21 anos & 10 anos \\
\hline B - Militar & 15 anos & 12 anos \\
\hline C - Militar & 11 anos & 6 anos \\
\hline D - Civil REDA & 20 anos & 1 ano \\
\hline E - Civil REDA & 5 anos & 3 meses \\
\hline
\end{tabular}

Fonte: Questionário de Investigação, Aplicado aos docentes de Matemática do CPMFPO, jun/ 2019

Através da Tabela 2, fica evidenciado pelo tempo de trabalho dos docentes de matemática do Colégio da Polícia Militar Francisco Pedro de Oliveira (CPMFPO),

\footnotetext{
4 O ENEM foi criado em 1998 para avaliar o domínio de competências pelos estudantes concluintes do ensino médio, a participação era voluntária. Em 2001, os alunos de escolas públicas passaram a ter isenção do pagamento da taxa de inscrição. O resultado do exame abre oportunidades de acesso à educação superior pública e particular e à educação profissional e tecnológica. Permite ainda a certificação do ensino médio.
} 
que a falta de profissionais efetivos pertencentes ao quadro de docentes impossibilita que seja dada sequência a realização de projetos em longo prazo, como o incentivo da leitura de paradidáticos relacionados a matemática, ação que nem sempre é apoiada por todos os docentes, principalmente quando o mesmo é temporário na unidade escolar, sente-se livre da responsabilidade de fazer parte de certos projetos que não sejam de seu interesse ou mesmo para não ter trabalho ou ainda por entender que o processo de ensino e aprendizagem da matemática se limita a cálculos aritméticos e algébricos.

A presença de dois professores militares no quadro de docentes, ainda que estes façam parte do quadro fixo de militares do colégio também não traduz um ponto de apoio ao desenvolvimento de ações diversificadas para implementar e aprimorar o processo de ensino e aprendizagem de matemática dos discentes do CPMFPO. Pois os mesmos não participam das reuniões com a coordenação pedagógica e demais docente da área, assim como, na maioria das vezes ficam alheios as ações pedagógicas desenvolvidas no colégio.

Ainda assim de forma contraditória, os professores militares acreditam na relevância dos dados gerados a partir da aplicação das avaliações externas, assim como, na possibilidade de validar o desempenho do trabalho dos mesmos. Surgindo a partir deste contexto a seguinte contradição: a consciência perante a importância de dados gerados com base em avaliações externas, mas ainda assim os referidos professores não aceitam a importância das reuniões pedagógicas e do trabalho feito em conjunto de forma a garantir o mínimo de continuidade de uma prática docente mais unificada.

Mesmo porque a ausência de continuidade de um trabalho pedagógico termina por prejudicar a formação dos discentes assim como tendi a diminuir a possibilidade desses discentes compreenderem a matemática como um conhecimento que não se encerra na sala de aula.

Assim sendo, a seguir será apresentado o perfil do discente de matemática do Colégio da Polícia Militar (CPM) e em especial do CPMFPO. 


\section{O Discente de Matemática do Colégio da Polícia Militar}

O corpo discente do Colégio da Polícia Militar (CPM) é formado tanto por filhos de militares quanto por filhos de civis, oriundos tanto de escolas públicas quanto de particulares e que em sua maioria são matriculados no CPM, às vezes contra a própria vontade, pelo fato de os pais entenderem que o colégio é, muitas vezes, a última chance de mudança de seu filho. Infelizmente tal obrigação gera um movimento de revolta que pode ou não ser dissipado a depender do nível de interação e das relações que sejam construídas dentro deste novo ambiente.

Os discentes do Colégio da Polícia Militar Francisco Pedro de Oliveira (CPMFPO) são oriundos do município de Candeias e de municípios vizinhos (Madre de Deus, São Francisco do Conde, Simões Filho e São Sebastião do Passé, Santo Amaro, Camaçari e Salvador), sendo a maioria de Simões Filho, Madre de Deus, São Francisco do Conde e São Sebastião do Passé. É interessante ressaltar que em decorrência da quantidade de estudantes, as prefeituras de Simões Filho e de Madre de Deus fornecem transporte.

A maioria dos discentes do CPMFPO provém da rede pública de ensino e, geralmente, não apresentam o conhecimento necessário para acompanhar a proposta pedagógica da série almejada. Com relação a faixa etária destes discentes, não há disparidade entre idade e série, devido ao próprio regimento escolar assim como ao edital de ingresso, que traz definida a faixa etária que os estudantes devem ter para concorrer a vaga referente a cada série pretendida.

O ingresso dos estudantes no CPMFPO ocorre em todas as séries tanto do Ensino Fundamental, quanto do Ensino Médio, desde que haja vaga para tal, sendo que $06^{\circ}$ ano do Ensino Fundamental é a única série que recebe, quase que em sua totalidade, discentes novatos salvo as exceções das vagas previamente ocupadas pelos discentes conservados. Tal fato evidencia a impossibilidade de garantir que um estudante ingresso no CPMFPO tenha sua formação no Ensino Fundamental II e no Ensino Médio realizada de forma completa, impossibilitando desta forma que ocorra o alinhamento adequado das competências e habilidades a serem adquiridas por este estudante. 
Desta forma, evidencia-se o fato de que ser um estudante do $9^{\circ}$ ano do Ensino Fundamental II do CPMFPO não é garantia de que o mesmo tenha sua formação nesta instituição desde o $6^{\circ}$ da mesma modalidade de ensino, sendo este um fato que não é considerado pelo SAEB.

Em sua maioria os discentes do Colégio da Polícia Militar Francisco Pedro de Oliveira (CPMFPO), assim como os demais discentes brasileiros, enxergam a matemática como um "bicho papão", e a todo o momento questionam acerca da real necessidade prática da matemática e meio que exigem um exemplo prático para cada conteúdo apresentado, como forma de obterem uma justificativa plausível para a existência da matemática na grade curricular (RODRIGUES e CHAVES, 2018).

Infelizmente esse quadro de incredulidade relacionada ao processo de ensino e aprendizagem da matemática traduz um quadro envolto em altos níveis de reprovação a cada unidade e consequentemente ao término do ano letivo.

O perfil dos estudantes de matemática do CPMFPO é caracterizado pela falta de base, de conhecimentos básicos como a realização de operações utilizando as quatro operações e a dificuldade de resolver situações problema, em virtude da dificuldade de interpretar as questões apresentadas, são dificuldades que acompanham estudantes de todas as séries nos dois níveis de ensino oferecidos pelo CPMFPO.

Enxergar qualquer que seja o conteúdo explanado como uma linguagem estrangeira desconhecida e automaticamente internalizar que não será aprendida de forma alguma e que precisa ser decorada, infelizmente é outra característica marcante dos estudantes do CPMFPO que acreditam na matemática, em sua maioria, como um conhecimento instantâneo necessário apenas para lograr a aprovação.

O processo de ensino aprendizagem da matemática remete a uma construção do conhecimento, que solicita dedicação e atenção tanto por conta do discente, quanto por conta do docente, pois a referida construção é um processo longo no qual o conhecimento é acumulado, ou seja: se identificam estágios, naturalmente não dicotômicos entre si, quando se dá a geração, a organização intelectual, a organização social e a difusão do conhecimento. Esses estágios são, normalmente, o objeto de estudo das 
teorias de cognição, das epistemologias, da história e sociologia, e da educação e política. O processo como um todo é extremamente dinâmico e jamais finalizado, e está obviamente sujeito a condições muito específicas de estímulo e de subordinação ao contexto natural, cultural e social. Assim é o ciclo de aquisição individual e social de conhecimento (D'AMBRÓSIO, 2005, [s/p]).

O conhecimento é um processo gradativo, acumulativo, dinâmico e que não cessa em si mesmo, pois a evolução da sociedade solicita a constante atualização do conhecimento adquirido.

Estar atento às questões culturais que rodeiam os discentes, inclusive do CPMFPO, conduzem a construção da ideia de que as avaliações devem sempre ser "premiadas", assim como as ações desenvolvidas no decorrer dos Projetos pedagógicos ainda que voltadas para ações sociais estas também precisam ser "premiadas" com base em algum tipo de pontuação. Pois infelizmente, na maioria das vezes os estudantes não compreendem que o mais importante em qualquer processo relacionado ao seu ensino aprendizagem é a conquista do conhecimento.

Ainda que em um contexto marcado pela cultura militar, os discentes do CPMFPO não conseguem despontar em relação as demais unidades do CPM, muitas vezes por conta da falta de compromisso, que em suas mentes seria apenas "um favor" para o colégio e não para eles próprios, tendo em vista que as conquistas individuais de cada indivíduo definem o diferencial dos mesmos enquanto profissionais mais bem preparados para o mercado de trabalho.

Para tal a valorização da cultura inerente a cada estudante assim como a exploração da cultura militar, podem influenciar no processo de ensino aprendizagem da matemática, quando é considerada a Etnomatemática ${ }^{5}$, que:

Não deve ser encarado como uma nova metodologia para o ensino de Matemática, mas como uma busca para entender os comportamentos matemáticos que não fazem parte da grade curricular do sistema educacional, uma metodologia/ferramenta que visa valorizar os saberes práticos construídos e transmitidos pelos diversos grupos culturais (SILVA et al, 2016, p. 5).

A hierarquização dos estudantes por meio da aquisição de patentes não parece ser um incentivo suficiente para garantir um nível de dedicação que supere a

5 Surgiu na década de 1970, com base em críticas sociais acerca do ensino tradicional da matemática, como a análise das práticas matemáticas em seus diferentes contextos culturais. 
busca pelas notas em prol da aquisição do conhecimento, como forma de garantir a um melhor desempenho tanto individual quanto coletivo dos alunos do CPMFPO.

Ainda assim, salvo raras exceções existem no CPMFPO estudantes que gostam de matemática, que se dedicam ao seu estudo e a preparação para a participação em eventos específicos da área, como por exemplo, a Olimpíada Brasileira de Matemática das Escolas Públicas $(\mathrm{OBMEP})^{6}$, que ano após ano tem trazido bons resultados para o colégio, com a entrega de menções honrosas e até mesmo de medalhas.

Outro evento relativo a matemática, do qual os estudantes do CPMFPO têm participado desde 2018 é a Olimpíada de Matemática do Estado da Bahia $(\mathrm{OMEBA})^{7}$, na qual ainda não foram conquistados bons resultados.

Em mais de uma edição da OBMEP o CPMFPO já teve estudantes premiados com medalhas e mantém sua participação com alunos recebendo menções honrosas. No que diz respeito as medalhas o CPMFPO teve até Décima quinta edição dois estudantes medalhistas, sendo eles: Alan Gualberto de S. de Freitas Pinho (que recebeu medalha de bronze em $2009^{8}$ na Quinta edição no Nível 1 (6º e $7^{\circ}$ ano), medalha de prata em $2010^{9}$ e $2011^{10}$, respectivamente na Sexta e Sétima edição no Nível 2 ( $8^{\circ}$ e $9^{\circ}$ ano) e medalha de ouro em $2015^{11}$ ) e Lucas Augusto de Freitas Pinho (medalha de bronze na Décima Primeira OBMEP, no Nível $2\left(8^{\circ}\right.$ e 9ำ ano)), curiosamente os estudantes são irmãos.

Como forma de atestar a caracterização do perfil dos estudantes do CPMFPO, foi realizada uma pesquisa com uma amostra de 87 discentes da

\footnotetext{
${ }^{6}$ Criada em 2005 para estimular o estudo da matemática e identificar talentos na área, a OBMEP é um projeto nacional dirigido às escolas públicas e privadas brasileiras, realizado pelo Instituto de Matemática Pura e Aplicada (IMPA), com o apoio da Sociedade Brasileira de Matemática (SBM), e promovida com recursos do Ministério da Educação e do Ministério da Ciência, Tecnologia, Inovações e Comunicações.

7 A OMEBA é uma competição promovida pelo Instituto de Matemática da Universidade Federal da Bahia (UFBA) é uma competição direcionada aos estudantes do Ensino Fundamental II e do Ensino Médio das escolas das redes pública e privada do estado da Bahia.

8 Fonte: http://premiacao.obmep.org.br/2009/verRelatorioPremiadosBronze-BA.do.htm. Acesso em: 17 dez 2019.

${ }^{9}$ Fonte: http://premiacao.obmep.org.br/2010/verRelatorioPremiadosPrata-BA.do.htm. Acesso em: 17 dez 2019.

10 Fonte: http://premiacao.obmep.org.br/2011/verMenuAlunosPremiados-BA.htm. Acesso em: 17 dez 2019.

11 Fonte: http://premiacao.obmep.org.br/2015/verRelatorioPremiadosBronze-BA.do.htm. Acesso em: $17 \mathrm{dez} 2019$.
} 
segunda série do Ensino Médio do referido colégio, no ano letivo de 2019. A escolha destes estudantes foi realizada tendo em vista o fato dos mesmos terem sido avaliados pela prova SAEB em 2017. A análise da referida pesquisa pode ser verificada no capítulo referente à Metodologia. No decorrer da supracitada pesquisa, pode-se apreender de forma mais claro e com referências estatísticas o olhar, de forma mais apurada, de nossos discentes pela matemática.

Diante das observações coletadas a partir da pesquisa aplicada, identificamos a assertiva necessidade de cultivar nos discentes a compreensão de que a matemática não se limita apenas a números e fórmulas e que a matemática também pode ser humana e social é um trabalho para os docentes que também desejam trabalhar a matemática de uma forma diferenciada e transpor as paredes da sala de aula levando a matemática presente no cotidiano para próximo de seus discentes.

\section{O Ensino da Matemática no Colégio da Polícia Militar}

A matemática é uma disciplina vista por grande parte dos estudantes como inútil e muitas vezes dispensável, sendo possível explicar tal visão tendo em vista, que muitos professores ainda lecionam tal disciplina de forma técnica, abstrata, sem contextualizá-la. E muitas vezes confirmando aos olhares dos estudantes percebese uma desconexão entre o ensino da matemática e seu cotidiano. Faz-se necessário ter a concepção de que o desenvolvimento do conhecimento matemático é:

\footnotetext{
Parte da satisfação da necessidade de comunicação entre os sujeitos para a realização de ações colaborativas. O desenvolvimento dos conteúdos matemáticos adquire, desse modo, característica de atividade. Esses conteúdos decorrem de objetos sociais para solucionar problemas, são instrumentos simbólicos que, manejados e articulados por certas regras acordadas no coletivo [...] os conhecimentos que vingam são aqueles que têm uma prova concreta quando testados na solução de problemas objetivos (MOURA, 2007, p. 50-51).
}

O ensino da matemática deve ter significados, é necessária uma mudança de hábitos, que proponha um ensino mais dinâmico, prazeroso e que aproxime os discentes da matemática com a qual ele convive em seu cotidiano e muitas vezes não se dá conta. Mesmo porque a matemática é uma ciência que se faz presente nas mais diversas situações do cotidiano e sua aplicabilidade se faz presente em uma variedade de relações entre o indivíduo e o mundo. 
Ainda assim, na maioria das vezes os discentes não apreendem essa ciência em função da ausência de uma relação concreta entre os conteúdos apresentados em sala de aula e as atividades fora dela, pois:

Para os professores da disciplina, matemática precisa tornar-se fácil, o que pressupõe que ela seja difícil. Estes identificam na voz do aluno que ela é considerada chata e misteriosa, que assusta e causa pavor, e por consequência, o aluno sente medo da sua dificuldade e vergonha por não aprendê-la. Como resultado de tantos sentimentos ruins que esta disciplina proporciona ao aluno, somado ao bloqueio em não dominar sua linguagem e não ter acesso ao seu conhecimento vem o sentimento de ódio pela matemática. Ódio, porque ela é difícil (SILVEIRA, 2014, p. 08).

No contexto atual se depara, muitas vezes com a imagem da disciplina que mais reprova e que não atrai a atenção dos discentes. Faz-se necessário que esta situação seja abolida do contexto do discente, até mesmo em situações comuns de sala de aula. Diante deste contexto evidencia-se que o trabalho do professor em sala de aula não se limita apenas a preocupação com o processo de ensino e aprendizagem da matemática, além disso:

O professor de Matemática lida com diversas variáveis que acabam contribuindo para a modelação dos conteúdos ensinados nas escolas, como o meio sociocultural, políticas e planos econômicos. Dessa forma, o conhecimento matemático trabalhado na escola acaba se adaptando em virtude dessas questões macro e, ainda, precisa atender à demanda escolar, adequando-se àquela comunidade. Portanto, até o conteúdo matemático chegar ao aluno, diversos procedimentos interferiram e o modificaram. (MANDLER et al, 2016, p. 108).

Considerar as diversas variáveis com as quais o professor de matemática precisa lidar, ou pelo menos a maior quantidade possível destas, favorece o processo de ensino aprendizagem da matemática, pois a apreensão do conteúdo matemático pelo discente está ligado a questões que vão desde o contexto cultural inerente a comunidade onde a escola está inserida até a estrutura física disponível no ambiente escolar.

Ainda considerando as variáveis com as quais o professor de matemática precisa lidar ao ministrar suas aulas o Conhecimento Matemático para o Ensino ${ }^{12}$ está organizado da seguinte forma:

O conhecimento comum do conteúdo; o conhecimento especializado do conteúdo; o conhecimento do conteúdo e dos alunos; o conhecimento do

12 O conceito de Conhecimento Matemático para o Ensino (ou MKT, da sigla em inglês para Mathematical Knowledge for Teaching) foi desenvolvido por Deborah Ball e seus colaboradores, pode ser interpretado como m aprimoramento da teoria da base do conhecimento de Shulman, numa interface direcionada para o ensino de Matemática. (MANDLER et al, 2016, p. 106) 
conteúdo e do ensino; o horizonte do conhecimento do conteúdo e o conhecimento do conteúdo e do currículo (MANDLER et al, 2016, p. 106).

Os cursos de licenciatura não formam os docentes para enfrentar tantas variáveis quanto as que surgem em uma sala de aula, nem ao menos dá ao docente, ferramentas que o capacite para identificar as mesmas. Infelizmente o professor aprende na prática e caso não seja perseverante e continue a investir em sua formação de forma continua não terá êxito em sua pratica pedagógica, ainda mais se considerarmos o fato de que o professor de matemática já lida com as dificuldades inerentes ao processo de ensino e aprendizagem da referida disciplina.

\section{Considerações}

A investigação evidenciou a falta de uma estrutura pedagógica capaz de auxiliar o CPMFPO a alcançar melhores níveis de desempenho no IDEB, assim como a ausência de um trabalho de conscientização junto aos discentes de forma a incentivar os mesmos a se dedicarem na busca de um melhor rendimento, assim como na busca da expansão de seus conhecimentos.

Também ficou evidenciado o fato de que a ausência de um trabalho de nivelamento dos discentes, desde a sua entrada no colégio assim como, a disponibilização de vagas para novatos apenas nas turmas do sexto e sétimo ano do Ensino Fundamental, poderiam auxiliar não só em um melhor desempenho na prova SAEB como também nas demais avaliações externas.

A ausência da presença de profissionais com formação inicial em matemática que pertençam ao quadro de professores efetivos da instituição, e que dessa forma possam realizar um trabalho contínuo, pautado no ensino aprendizagem da matemática, de forma que esta ultrapasse os conteúdos pelos conteúdos e seja desenvolvida de forma concatenada com a cultura e vivências de cada estudante. Pois pensar em êxito nas avaliações externas sem modificar as concepções dos discentes de que a matemática se resume a resolução de problemas, que para eles não fazem sentido e não possuem qualquer relação com suas vivências.

Ainda que seja difícil o CPMFPO pode reverter o quadro de uma instituição que poderia alcançar melhores resultados, mas não o fazem, pois sempre ficam no meio da jornada em busca de resultados exitosos. Mas para tal, uma mudança de hábitos é imprescindível, sendo esta efetivada desde a mudança de postura dos docentes de matemática, que independente de serem efetivos ou não precisam 
demonstrar maior comprometimento com a busca por uma matemática voltada para uma educação de qualidade e significativa.

De acordo com as pesquisas pode-se afirmar que os docentes de matemática não podem ensinar sem acreditarem na veracidade do que estão fazendo e da real preparação que precisam ter para escrever uma proposta pedagógica para o ensino da matemática no Colégio da Polícia Militar Francisco Pedro de Oliveira de Candeias (CPMFPO), que não seja apenas voltada para a obtenção de resultados mas sim para a aquisição do conhecimento matemático de forma que os bons resultados sejam consequências e não os únicos objetivos a serem traçados.

\section{Referências}

ALMEIDA, L. C; DALBEN, A; FREITAS, L. C. O IDEB: Limites e Ilusões de uma Política Educacional. Campinas: Educ. Soc., 2013.

COLÉGIO DA POLÍCIA MILITAR FRANCISCO PEDRO DE OLIVEIRA. Projeto Político Pedagógico do Colégio da Polícia Militar de Candeias. Candeias: [s.n], 2012.

D’AMBRÓSIO, U. Sociedade, cultura, matemática e seu ensino. Educação e Pesquisa. São Paulo: Pro-Posições, 2005.

GADOTTI, M. A Escola e o Professor: Paulo Freire e a paixão de ensinar. 1. ed. São Paulo: Publisher Brasil, 2007.

GIL, A. C. Métodos e técnicas de pesquisa social. 6. ed. São Paulo. Atlas, [s.I], 2008.

ÍNDICE DE DESENVOLVIMENTO DA EDUCAÇÃO BÁSICA (IDEB), na Série Documental. Texto para Discussão no 26, Nota Técnica Índice de Desenvolvimento da Educação Básica - IDEB, 2007.

LUBISCO, N. M. L., VIEIRA, S. C. Manual de estilo acadêmico: trabalhos de conclusão de curso, dissertação e teses. EDUFBA, [s.I], 2013.

MANDLER, M. L. et al. A Epistemologia da Educação Matemática e o conhecimento do professor de Matemática. II Colóquio Luso-Brasileiro de Educação. Santa Catarina: Colbeduca 2016.

MOURA, M. Matemática na infância. In: MIGUEIS, M. R., AZEVEDO, M. G. (Org.). Educação Matemática na infância: abordagens e desafios. Vila Nova de Gaia. Gailivro, 2007.

RODRIGUES, A. M. S., CHAVES, S. N. Diga-me que matemática sabes e eu te direi o que podes. Em teia, [s.I]: Revista de Educação Matemática e Tecnológica Iberoamericana. v. 9, n. 2, 2018. 
SILVA, H. L. et al. Etnomatemática: a relação da matemática, da cultura e dos Saberes. XII Encontro Nacional de Educação Matemática. Educação Matemática na Contemporaneidade: desafios e possibilidades. São Paulo: [s.I], 2016.

SILVEIRA, R. A. Matemática é difícil: Um sentido pré-construído evidenciado na fala dos alunos. [s.p]: Contextualizando o problema, 2014. 